\title{
Fishing Gear and Set Methodology Models for Target Species Fishing Success in Gulf of Mexico Longline Reef Fishing
}

\author{
By Alexandria E. Rivard* \\ Wyndylyn von Zharen ${ }^{\dagger}$
}

\begin{abstract}
Bycatch of non-target species in many fisheries can contribute to mortality of discarded individuals and negative environmental impacts. The objective of this study was to predict the capability of commercial fishers to successfully obtain a targeted species of grouper, snapper, or porgy based on the fishing gear and set configuration employed. Data were collected by the Southeast Fisheries Science Center (SEFSC) Galveston Reef Fish Observer Program from 2006-2014 as mandated under the Gulf of Mexico Fishery Management Council (GMFMC) Reef Fish Fishery Management Plan. Binomial regression models using the complementary log-log link function (except red grouper, log odds link function) were constructed in $\mathrm{R}$ version 3.2.3 using backwards regression to predict target species fishing success using variables directly manipulated by fishers, including soak time, fishing depth, main line length, hooks deployed, gangion length, hook distance, and the temporal variables month and year. An ANOVA was used to calculate the significance of the final model against the null model, and McFadden's $R^{2}\left(R_{M c F}^{2}\right)$ was calculated to determine the proportional reduction in error variance from the null model. Significant models were generated for speckled hind $\left(p<0.01, R_{M c F}^{2}=0.204\right)$, red grouper $\left(p<0.01, R_{M c F}^{2}=0.023\right)$, scamp $\left(p<0.01, R_{M c F}^{2}=0.183\right)$, gag grouper $\left(p<0.01, R_{M c F}^{2}=0.090\right)$, red snapper $(p<0.01$, $\left.R_{M c F}^{2}=0.059\right)$, mutton snapper $\left(p<0.01, R_{M c F}^{2}=0.330\right)$, jolthead porgy $(p<0.01$, $\left.R_{M c F}^{2}=0.124\right)$, and red porgy $\left(p<0.01, R_{M c F}^{2}=0.120\right)$. These models ultimately serve as guidelines for fishers to adjust fishing practices to improve the likelihood of successfully obtaining the species targeted, which may reduce bycatch mortality of non-target species and its resulting environmental impacts.
\end{abstract}

Keywords: Bycatch reduction, Commercial longline fishing, Gulf of Mexico, Fishery, Species selectivity.

\section{Introduction}

Longline Fishing

Longline fishing is permitted for a number of species in the Gulf of Mexico including several species of snapper (red, Lutjanus campechanus; and mutton, Lutjanus analis), grouper (speckled hind, Epinephelus drummondhayi; red, Epinephelus morio; scamp, Mycteroperca phenax; and gag, Mycteroperca microlepis), porgy (jolthead, Calamus bajonado; and red, Pagrus pagrus), and

${ }^{*}$ PhD Candidate, Texas A\&M University at Galveston, USA.

${ }^{\dagger}$ Professor Emerita, Texas A\&M University at Galveston, USA. 
other reef fish (Gulf of Mexico Fishery Management Council, 2010a). Modern longline fishing methods originated in Japan in the $19^{\text {th }}$ century. This fishing gear consists of a long mainline attached to a series of floats to suspend the line at depth, and a gangion line (a moderate weight line bearing hooks) suspended from the main line, and a hook (typically J-style, ringed, or circle hooks). Fishers may adjust the length and depth of the gear set and hook shape and size based on the desired species (Watson and Kerstetter, 2006).

Pelagic longline fisheries necessitate a relatively moderate level of regulation, as compared with methods such as bottom trawls and gillnet which pose serious environmental threats and require more stringent regulation. Possible ecological impacts of pelagic longlines include risk of entanglement and bycatch of nontarget species including protected species (Chuenpagdee et al., 2003). Management of reef fish fisheries in the Gulf of Mexico has been overseen by the Gulf of Mexico Fishery Management Council (GMFMC) since the implementation of the Fishery Management Plan for the Reef Fish Resources of the Gulf of Mexico in November 1984 (Waters, 2001). The original plan, initiated in response to declining fish stocks, included gear prohibitions, minimum fish-size limits, and data reporting requirements (Gulf of Mexico Fishery Management Council, 2010b).

\section{Bycatch Concerns}

In the past few decades, fishery management has begun to adopt a holistic, ecosystem-based focus in favor of the traditional species-by-species management approach. This management style requires consideration of prey and predator species, environmental impacts, and interactions of these components (Kennelly and Broadhurst, 2002; Pikitch et al., 2004). Once managers have identified the extent to which these considerations factor into their ecosystem of interest, managers must attempt to integrate these components into a cohesive management plan. While longline fishing imposes less environmental damage than more invasive methods like shrimp fishing, managers must still be aware of potential risks including disruption of trophic interactions (Chuenpagdee et al., 2003). While catches of target species are closely regulated, catches of non-target species may have unexpected deleterious impacts. The intent of this study is to assess gear configurations that contribute to increased probability of successfully catching the intended species.

Bycatch of non-target species is a concern in longline fishery management. Herein, bycatch is defined per Alverson (1999) as "...the capture of any species, size of species, or sex of species that is not the primary target(s) of a fishing activity." A "target species" is defined as a catch of a legally retainable fish coded as "kept for consumption" by fishery observers. A significant portion of the literature focuses on avoiding bycatch of species outside the fishery (e.g. turtles, marine mammals, and seabirds) (Belda and Sánchez, 2001; Southwood et al., 2008; Piovano et al., 2010). Incidental capture of these species has contributed to population declines in several instances, and requires further study (Lewison et al., 2004). However, bycatch of fishes that are not retained also carries 
significant negative consequences and serves as the major concern of this research. Discarded fish may experience physical injury or stress contributing to later negative impacts to the individual, lowering their fitness and potentially resulting in mortality (Alverson, 1999; Davis, 2005). While measures can be taken to minimize the adverse effects of catching and handling fish, configuring gear to minimize the potential for non-target fish catch may ultimately prevent stress or injury prior to its occurrence.

NOAA Fisheries (2016) aim to, "promote productive and sustainable fisheries and improve the recovery and conservation of protected resources," through an ecosystem-based management approach to its national bycatch reduction strategy. While several federal laws mandate bycatch prevention (e.g. MagnusonStevens Fishery Conservation and Management Act, Marine Mammal Protection Act, Endangered Species Act), each quantifies and manages bycatch differently. The national bycatch reduction strategy aims to unify these approaches through strengthening monitoring efforts, clarifying research needs, improving discard and take estimates, improving management measures, strengthening the effectiveness of law enforcement, and improving communication within NOAA Fisheries and with stakeholders. One strategy identified for improving management measures to reduce bycatch is to develop and implement speciesspecific bycatch reduction measures (NOAA Fisheries, 2016). Through evaluating the most effective means of catching target species in the longline fishery, this research may ultimately provide the basis for species-specific bycatch reduction through altering fishing techniques.

\section{Management of Species of Evaluated, 2006-2014}

Fishing success must be considered in the context of the relevant management regulations. The Gulf of Mexico Fishery Management Council is responsible for preparing fishery management plans for federal waters. The federal commercial fishing regulations for several species studied herein mandate minimum length limits and catch quotas which may influence fishing success.

Two porgy species, two snapper species, and four grouper species were included in this study. Of the species studied, red porgy and jolthead porgy are not included in the Gulf of Mexico Reef Fish Fishery Management Plan (GMRFFMP) (Gulf of Mexico Fishery Management Council, 2015). Mutton snapper have been managed simply, under a 12-inch total length minimum (GMRFFMP amendment 5) through the duration of the study period, with no trip catch limits or quotas. While these species may be managed at the state level, federal regulations have not been in effect during the study period. However, both snapper species (mutton and red) and all four grouper species (red, scamp, gag, and speckled hind) have been regulated for the duration of the study period.

Red snappers have been managed by total length limits and catch quotas throughout the study period. In 2006 and 2007, a class 1 or class 2 license allowed trip limit catches of 2,000 pounds for the former or 200 pounds for the latter, with a 15-inch minimum length. The fishery was closed in January, and opened from noon on the $1^{\text {st }}$ to noon on the $10^{\text {th }}$ of each month until the sub- 
quota of 3.06 million pounds (mp) was filled (via a March 1997 regulatory amendment). The remainder of the total 4.65-million-pound quota was released starting in October, following the same pattern until December $31^{\text {st }}$. In 2008, the fishery transitioned to an individual fishing quota (IFQ) system, with a 13inch total length limit and a total quota of $2.55 \mathrm{mp}$ (GMRFFMP amendment 27). These regulations remained in effect in 2009. In 2010, 2012, and 2013, the quotas were increased to $3.542 \mathrm{mp}$ (2010 regulatory amendment for red snapper), $3.664 \mathrm{mp}$ (2011 regulatory amendment for red snapper), and $4.121 \mathrm{mp}$ for 2012 and $4.257 \mathrm{mp}$ for 2013 (both via 2012 regulatory amendment for red snapper) with the 13-inch length limit retained throughout.

Gag grouper are also managed under length and catch limits. From 20062008, gag groupers were subjected to a 24-inch total length limit, and managed under the shallow water grouper overall quota of $8.80 \mathrm{mp}$ gw, with seasonal closures from February 15 to March 15 annually (Secretarial Amendment 1, 2004). A separate gag grouper quota (included under the total shallow water grouper quota) was instated at $1.32 \mathrm{mp}$ for $2009,1.41 \mathrm{mp}$ for 2010 , and 1.49 mp for 2011 (GMRFFMP amendment 30B). In 2011, an emergency interim rule restricted the gag grouper quota to 430,000 pounds of the net quota. The quota was lowered to $0.567 \mathrm{mp}$ in 2012, $0.708 \mathrm{mp}$ in 2013, $0.835 \mathrm{mp}$ in 2014 (GMRFFMP amendment 32). Amendment 32 also lowered the total length minimum to 22 inches.

Scamp has been managed under an IFQ program with composite grouper quotas for the duration of the study period, with a 16-inch total length restriction throughout. From 2006-2008, scamp were included in the shallow water grouper quota of $8.80 \mathrm{mp}$ gw (Secretarial Amendment 1, 2004). The shallow water grouper quota was set to $7.48 \mathrm{mp}$ for $2009,7.57 \mathrm{mp}$ for 2010 , and 7.65 mp in 2011 on (GMRFFMP amendment 30B). In all years, scamp caught after filling the shallow water grouper IFQ can be counted towards the deep-water grouper IFQ.

Red groupers were regulated under a separate quota throughout the study period. Minimum length was set at 20 inches but the length was lowered to 18 inches for the remaining years (Amendment 30B). Seasonal closures from February 15 to March 15 were in effect for 2006-2008 (November 2005 regulatory amendment, removed by amendment 30B). The catch quota was set to $5.31 \mathrm{mp}$ gw for 2006-2008, and subsequently raised to $5.75 \mathrm{mp}$ gw for 2009 (GMRFFMP amendment 30B). A 2010 regulatory amendment lowered the quota to $4.32 \mathrm{mp}$. From 2012 on, the red grouper quota was set at $6.03 \mathrm{mp}$ (GMRFFMP amendment 32).

Speckled hinds have not been regulated by a minimum size at any point during the study period. From 2006-2009, a trip limit of 6,000 pounds was in effect for groupers, and speckled hinds were managed under the $1.02 \mathrm{mp} \mathrm{gw}$ deep water grouper quota (Secretarial Amendment 1, 2004). In 2010 and 2011, speckled hinds were moved into the shallow water grouper quota (GMRFFMP amendment 30B).

Seasonal spatial fishing restriction was implemented in 2010 with GMRFFMP amendment 31. Use of bottom longline gear for reef fish was 
prohibited in the Gulf of Mexico east of $85^{\circ} 30^{\prime} \mathrm{W}$ longitude within the United States exclusive economic zone. Though not a large area (spanning only approximately four degrees latitude and two degrees longitude) this closure may contribute to apparent declines in catch success during these months and for years 2010 and later.

\section{Bycatch Reduction Measures}

Fishing technology developed with the intent of catching as many fish as possible. Bycatch and discard of fish has been documented as early as biblical times, and legal prohibition of bycatch dates back to the $14^{\text {th }}$ century. However, the technological advances made during the $20^{\text {th }}$ century allowed humans to extract fish at a rate faster than the population could replace them, ultimately leading to declines in several economically valuable fish stocks. Management and regulation of fisheries in the United States began in earnest with the institution of the Magnuson Act of 1976, and intensified with stricter laws and management plans through the 1980s (Kennelly and Broadhurst, 2002). As public pressure to improve fishery management practices has increased over the last several decades, bycatch reduction strategies have become a focus for managers and industry (Alverson and Hughes, 1996; Hall et al., 2000; Kennelly and Broadhurst, 2002; Rodger and von Zharen, 2011).

A number of bycatch mitigation methods have been employed in the bottom longline fishery worldwide. Altering hook shape and size has proven useful in reducing bycatch of stingrays, and setting lines deeper or at night can reduce seabird hooking and entanglement (Hall et al., 2000; Belda and Sánchez, 2001; Piovano et al., 2010). However, hook size selectivity appears to vary among species, with some bycatch reduction for certain species and no apparent effect for others (Erzini et al., 1996). Bait size, though potentially confounded with hook size, did not appear to affect the species and size selectivity of Portuguese red sea breams (Erzini et al., 1998). However, in the Norwegian haddock fishery, increasing bait size successfully reduced bycatch of undersized individuals (Huse and Soldal, 2000). Shortening gear soak times may contribute to a decline in shark bycatch, without reducing catches of red grouper or red snapper (Mitchell, 2014). Similarly, bycatch of elasmobranch species in the Portuguese artisanal hake fishery was significantly reduced following the removal of hooks set at deeper depths, with only minor reduction of target species catch (Coelho et al., 2003).

While bycatch reduction is a worthwhile goal, fishery managers must be conscientious of bycatch reduction techniques that may negatively impact target catch. For instance, utilizing hooks with inedible plastic bodies successfully reduced bycatch of undersized haddock, but reduced overall catch (Huse and Soldal, 2000). Bycatch reduction technologies that negatively impact fishing success of the target species are unlikely to be adopted voluntarily by the fishing industry, and will have a negative financial impact on fishers if mandated. Ultimately, bycatch reduction methods should aim to improve selectivity without reducing the catch of the target species. 
The objective of this study is to identify fishing gear and set characteristics that favor catching only the target species. Herein, catch of the target species is defined as a "success", and "successful fishing" as those practices that result in the greatest number of successes. Prior research has not addressed small scale temporal (e.g. month-to-month) changes in fishing success and has not included hook placement parameters. For the intent of this study, fish that were not legally retained for commercial purposes were considered bycatch. Presumably, fishers are not targeting a species after the required quotas have been filled, though bycatch as a result of regulatory noncompliance is still likely occurring. Therefore, quota restrictions should have only limited impact on fishing success. However, factors contributing to the lowering of the quota (e.g. population declines) may influence fishing success. For species with length restrictions, success may improve or decline if length restrictions are lowered or raised, and therefore these factors will be considered in addressing the results. Ultimately, the intent of this study is to identify the best fishing practices for each target species. These models will contribute to reducing bycatch (and thereby improve the fishery system), and reduce the economic investment of time and capital which will strengthen the fishing community.

\section{Methods}

The Southeast Fisheries Science Center (SEFSC) Galveston Reef Fish Observer Program provided data pertaining to the commercial bottom longline reef fishery in the Gulf of Mexico for fishing depths less than 328 feet. This program was initiated in July 2006 per Amendment 22 of the GMFMC Reef Fish FMP, and data collection is conducted by trained observers onboard commercial fishing vessels (Scott-Denton et al., 2011; National Marine Fisheries Service, 2013).

The goals of the reef fish observer program include: characterization of finfish bycatch; estimation of finfish discard and mortality; and estimation of bycatch of protected species. To that end, observers report: trip, vessel, environmental, and gear characteristics; fish and protected species composition and disposition; size of target species caught; and catch-per-unit effort (CPUE) trends (Scott-Denton and Williams, 2013). The data collected by observers on bottom longline reef fish fishing vessels in the Gulf of Mexico are the basis for this study. Per NOAA Administrative Order 216-100 and a non-disclosure agreement with NMFS SEFSC, raw data are confidential.

All statistical analysis was conducted using $\mathrm{R}$ version 3.2.3 "Wooden Christmas-Tree".

The purpose of the models derived in this chapter is to predict the success of obtaining a given target species as opposed to any other reef fish species. For the purpose of this study, a "success" was considered a fish of the target species (the species fishers intended to catch during the fishing set) that was

\footnotetext{
${ }^{1}$ Mention of trade names or commercial companies is for identification purposes only and does not imply endorsement by the National Marine Fisheries Service, NOAA.
} 
coded as "kept for consumption purposes" by the fishery observers. A "failure" was considered catch of any other reef fish species or an individual of the target species that was not kept; bycatch of protected species (e.g. marine mammals and turtles) was not included, nor were empty hooks. Only species with more than 500 catches of individuals were considered. Blacknose sharks (7 individuals kept), sharpnose sharks (11 individuals kept), and leopard toadfish (3 individuals kept) were excluded from the analysis due to the limited number of successes. Prior to analysis, data entries with missing values were removed from the dataset as necessitated by the analysis. The total number of catches included in the sample after removing entries with missing information was 339,179. The species analyzed and the number of successes are given in Table 1 .

Only variables that can be directly manipulated by fishers were included in the analysis, as these variables can be controlled and are therefore the useful for management purposes. Therefore, abiotic factors (e.g. salinity, water temperature) and biotic and population factors (e.g. prey availability, population size) were excluded. Year has been included to allow for the determination of how changes over time contribute to the variance. Excluded biotic and abiotic factors presumably contribute to the unexplained variance in the models. Years have been numbered from year 1 (2006) to 9 (2014). The following explanatory variables were included in the analysis: soak time in hours; fishing depth in feet; main line length in miles; hooks deployed (actual when available, and approximate as given by the observer otherwise); gangion length in feet; hook distance in feet; and month of the year. The dependent variable was success or failure of obtaining the target species.

Table 1. The Species Names and Number of Successful Catches (Coded by Observers as kept for Consumption)

\begin{tabular}{|c|c|c|}
\hline Common Name & Scientific Name & $\begin{array}{c}\text { Number of } \\
\text { Successes }\end{array}$ \\
\hline Jolthead Porgy & Calamus bajonado & 1162 \\
\hline Speckled Hind & $\begin{array}{c}\text { Epinephelus } \\
\text { drummondhayi }\end{array}$ & 468 \\
\hline Red Grouper & Epinephelus morio & 187171 \\
\hline Red Snapper & Lutjanus campechanus & 5316 \\
\hline Mutton Snapper & Lutjanus analis & 2147 \\
\hline Scamp & Mycteroperca phenax & 6446 \\
\hline Gag Grouper & Mycteroperca microlepis & 3593 \\
\hline Red Porgy & Pagrus pagrus & 587 \\
\hline
\end{tabular}

Binomial regression models were constructed in $\mathrm{R}$ using the complementary $\log -\log$ link function for all species (except red grouper) to account for the low number of successes out of the total dataset. For red grouper, the log odds link function was used as the success rate was very high. The final model was determined using backwards regression. Variables were tested for significance using the "drop1" command in $\mathrm{R}$, which computes the significance of all single terms in the model. The least significant variable was removed at each step 
until all variables remaining were significant at $p \leq 0.01$. Models were compared using the Bayesian information criterion (BIC) to verify that the final model was indeed the most suitable for the data. An ANOVA was used to assess the significance of the final model when compared with the null model. Null models included only the intercept. The estimate coefficients given in the final model for month compare each month relative to a baseline of April (alphabetically first); and for year, compare each year to year 1. The coefficients for April and year 1 are presumed to be 1 .

McFadden's $R^{2}\left(R_{M c F}^{2}\right)$ was calculated to determine the proportional reduction in error variance using the equation below, where $L_{M}$ is the $\log$ likelihood of the final model, and $L_{0}$, the log-likelihood of the null (intercept only) model (Allison, 2014):

$R_{M c F}^{2}=1-\frac{\ln L_{M}}{\ln L_{0}}$

A Cook's distance plot was evaluated for the presence of influential points. For the red grouper log odds model, the coefficients represent the change in the $\log$ odds of success associated with the variable of interest, when all other variables are held constant. For all other models, the coefficients represent a change in the complementary log-log odds.

\section{Results}

\section{Jolthead Porgy}

The final model for jolthead porgy predicts fishing success as a function of fishing depth, gangion length, hook distance, hook count, month, and year (Table $2)$. No issues with VIF or influential points were identified, and the model was a significant improvement from the null model $(p<0.01)$. All months except January and October were significant improvements as compared with the April baseline, and all years except year 2 were significant against year 1 (Table 2). Fishing depth, gangion length, and mainline length increases contributed to increased probability of catching jolthead porgy, while increases in hook distance and hook count contributed to declines (Table 2). The model represents an approximately $12.4 \%$ improvement over the null model $\left(R^{2}{ }_{M c F}=0.124\right)$. 
Table 2. The Results of the Binomial Regression Model for Jolthead Porgy Derived by Backwards Regression $R_{M c F}^{2}=0.124, p<0.01$

\begin{tabular}{|l|c|c|c|}
\hline & Estimate & Std. Error & $\boldsymbol{p}$-value \\
\hline (Intercept) & -11.267 & 0.478 & 0.000 \\
\hline FishingDepth & 0.015 & 0.001 & 0.000 \\
\hline GangLength & 0.037 & 0.013 & 0.005 \\
\hline HookDistance & -0.022 & 0.003 & 0.000 \\
\hline MainLineMi & 0.183 & 0.025 & 0.000 \\
\hline Hooks & -0.001 & 0.000 & 0.000 \\
\hline MonthAug & 1.133 & 0.185 & 0.000 \\
\hline MonthDec & 0.811 & 0.209 & 0.000 \\
\hline MonthFeb & 0.585 & 0.164 & 0.000 \\
\hline MonthJan & 0.200 & 0.185 & 0.281 \\
\hline MonthJul & 1.235 & 0.163 & 0.000 \\
\hline MonthJun & 1.956 & 0.143 & 0.000 \\
\hline MonthMar & 0.890 & 0.154 & 0.000 \\
\hline MonthMay & 0.504 & 0.176 & 0.004 \\
\hline MonthNov & 1.626 & 0.169 & 0.000 \\
\hline MonthOct & 0.067 & 0.265 & 0.801 \\
\hline MonthSep & -0.981 & 0.315 & 0.002 \\
\hline Year2 & 0.277 & 0.546 & 0.612 \\
\hline Year3 & 1.201 & 0.724 & 0.097 \\
\hline Year4 & 2.049 & 0.434 & 0.000 \\
\hline Year5 & 1.214 & 0.433 & 0.005 \\
\hline Year6 & 1.841 & 0.426 & 0.000 \\
\hline Year7 & 1.217 & 0.442 & 0.006 \\
\hline Year8 & 2.020 & 0.421 & 0.000 \\
\hline Year9 & 0.608 & & 0.000 \\
\hline
\end{tabular}

\section{Speckled Hind}

The resulting binomial regression model for speckled hind included fishing depth, hook count, month, and year (Table 3). No issues with VIF or influential points were identified, and the model was a significant improvement from the null model $(p<0.01)$. Increased fishing depth and hook count contributed positively to successfully catching speckled hind (Table 3). The months of March, October, and November significantly increased the complementary loglog likelihood of catching speckled hind when compared with the April baseline (Table 3). While year was significant within the model, no individual years represented a significant deviation from the year 1 baseline. The model constitutes a $20.4 \%$ improvement over the null model $\left(R_{M c F}^{2}=0.204\right)$. 
Table 3. The Results of the Binomial Regression Model for Speckled Hind Derived by Backwards Regression $R_{M c F}^{2}=0.204, p<0.01$

\begin{tabular}{|l|c|c|c|}
\hline & Estimate & Std. Error & $\boldsymbol{p}$-value \\
\hline (Intercept) & -17.648 & 1.111 & 0.000 \\
\hline FishingDepth & 0.036 & 0.001 & 0.000 \\
\hline Hooks & 0.001 & 0.000 & 0.001 \\
\hline MonthAug & 0.849 & 0.242 & 0.001 \\
\hline MonthDec & 0.164 & 0.330 & 0.619 \\
\hline MonthFeb & 0.298 & 0.224 & 0.184 \\
\hline MonthJan & 0.569 & 0.261 & 0.029 \\
\hline MonthJul & 0.501 & 0.237 & 0.035 \\
\hline MonthJun & 0.529 & 0.221 & 0.017 \\
\hline MonthMar & 1.010 & 0.219 & 0.000 \\
\hline MonthMay & 0.319 & 0.270 & 0.237 \\
\hline MonthNov & 0.792 & 0.303 & 0.009 \\
\hline MonthOct & 1.250 & 0.273 & 0.000 \\
\hline MonthSep & -0.939 & 0.486 & 0.053 \\
\hline Year2 & 1.440 & 1.066 & 0.177 \\
\hline Year3 & -10.825 & 162.671 & 0.947 \\
\hline Year4 & 2.223 & 1.026 & 0.030 \\
\hline Year5 & 2.587 & 1.013 & 0.011 \\
\hline Year6 & 1.808 & 1.017 & 0.075 \\
\hline Year7 & 1.357 & 1.033 & 0.189 \\
\hline Year8 & 2.208 & 1.014 & 0.029 \\
\hline Year9 & -0.621 & 1.109 & 0.576 \\
\hline & & & \\
\hline & & & \\
\hline
\end{tabular}

\section{Red Grouper}

Because of the high number of red grouper catches in the dataset $(n=$ 187,171), the log odds link function was used for the binomial regression model. The final model for red grouper included soak time, gangion length, hook distance, mainline length, hook count, month, and year (Table 4). No issues with VIF or influential points were identified, and the model was a significant improvement from the null model $(p<0.01)$. Increased mainline length and hook count significantly improved fishing success of red grouper, whereas soak time, gangion length, and hook distance contributed to decreased success (Table 4). All months except May represented significant changes from the April baseline, with increased success in January, February, September, October, and December, and decreases in March, June, July, August, and November (Table 4). While the model was significantly better than the null model, the final model represents only a $2.3 \%$ improvement $\left(R_{M c F}^{2}=0.023\right)$. 
Table 4. The Results of the Binomial Regression Model for Red Grouper Derived by Backwards Regression $R_{M c F}^{2}=0.023, p<0.01$

\begin{tabular}{|l|c|c|c|}
\hline & Estimate & Std. Error & $\boldsymbol{p}$-value \\
\hline (Intercept) & -0.892 & 0.028 & 0.000 \\
\hline CalcSoakTime & -0.030 & 0.003 & 0.000 \\
\hline GangLength & -0.021 & 0.001 & 0.000 \\
\hline HookDistance & -0.002 & 0.000 & 0.000 \\
\hline MainLineMi & 0.061 & 0.003 & 0.000 \\
\hline Hooks & 0.000 & 0.000 & 0.000 \\
\hline MonthAug & -0.101 & 0.018 & 0.000 \\
\hline MonthDec & 0.163 & 0.014 & 0.000 \\
\hline MonthFeb & 0.186 & 0.011 & 0.000 \\
\hline MonthJan & 0.070 & 0.014 & 0.000 \\
\hline MonthJul & -0.046 & 0.016 & 0.005 \\
\hline MonthJun & -0.065 & 0.015 & 0.000 \\
\hline MonthMar & -0.029 & 0.010 & 0.006 \\
\hline MonthMay & -0.024 & 0.013 & 0.053 \\
\hline MonthNov & -0.049 & 0.014 & 0.000 \\
\hline MonthOct & 0.041 & 0.012 & 0.001 \\
\hline MonthSep & 0.069 & 0.011 & 0.000 \\
\hline Year2 & 0.345 & 0.028 & 0.000 \\
\hline Year3 & 0.191 & 0.041 & 0.000 \\
\hline Year4 & 0.296 & 0.025 & 0.000 \\
\hline Year5 & 0.379 & 0.021 & 0.000 \\
\hline Year6 & 0.696 & 0.021 & 0.000 \\
\hline Year7 & 0.714 & 0.022 & 0.000 \\
\hline Year8 & 0.941 & 0.021 & 0.000 \\
\hline Year9 & 0.893 & & 0.000 \\
\hline & & & \\
\hline & & 023 & \\
\hline
\end{tabular}

\section{Red Snapper}

The final model for red snapper predicts fishing success using fishing depth, gangion length, mainline length, hook count, month, and year (Table 5). No issues with VIF or influential points were identified, and the model was a significant improvement from the null model $(p<0.01)$. All months were significantly different from the April baseline, with decreased success in June, July, and August, and increased success in other months (Table 5). While year 2 represented a decline in success and year 7 was not significant, all other years represent a significant increase in fishing success (Table 5). Mainline length contributed to a decline in fishing success, but fishing depth, gangion length, 
and hook count were all significantly positive (Table 5 ). The model represents $5.9 \%$ improvement over the null model $\left(R_{M c F}^{2}=0.059\right)$.

Table 5. The Results of the Binomial Regression Model for Red Snapper Derived by Backwards Regression $R_{M c F}^{2}=0.059, p<0.01$

\begin{tabular}{|l|c|c|c|}
\hline & Estimate & Std. Error & $p$-value \\
\hline (Intercept) & -7.632 & 0.173 & 0.000 \\
\hline FishingDepth & 0.011 & 0.000 & 0.000 \\
\hline GangLength & 0.059 & 0.005 & 0.000 \\
\hline MainLineMi & -0.101 & 0.013 & 0.000 \\
\hline Hooks & 0.000 & 0.000 & 0.000 \\
\hline MonthAug & -0.935 & 0.132 & 0.000 \\
\hline MonthDec & 1.108 & 0.064 & 0.000 \\
\hline MonthFeb & 0.433 & 0.057 & 0.000 \\
\hline MonthJan & 0.512 & 0.064 & 0.000 \\
\hline MonthJul & -0.697 & 0.098 & 0.000 \\
\hline MonthJun & -1.402 & 0.110 & 0.000 \\
\hline MonthMar & 0.279 & 0.060 & 0.000 \\
\hline MonthMay & 0.223 & 0.068 & 0.001 \\
\hline MonthNov & 0.713 & 0.066 & 0.000 \\
\hline MonthOct & 0.198 & 0.075 & 0.008 \\
\hline MonthSep & 0.238 & 0.063 & 0.000 \\
\hline Year2 & -1.228 & 0.321 & 0.000 \\
\hline Year3 & 2.001 & 0.177 & 0.000 \\
\hline Year4 & 0.799 & 0.156 & 0.000 \\
\hline Year5 & 0.947 & 0.144 & 0.000 \\
\hline Year6 & 0.764 & 0.145 & 0.000 \\
\hline Year7 & 0.041 & 0.155 & 0.792 \\
\hline Year8 & 0.984 & 0.143 & 0.000 \\
\hline Year9 & 0.740 & 0.154 & 0.000 \\
\hline & & & \\
\hline & & & \\
\hline
\end{tabular}

\section{Mutton Snapper}

The final model for mutton snapper predicts fishing success using soak time, fishing depth, gangion length, hook distance, month, and year (Table 6). No issues with VIF or influential points were identified, and the model was a significant improvement from the null model $(p<0.01)$. Months February, March, and November were not significant when compared to the April baseline (Table 6). January, May, June, August, September, October, November, and December had a negative impact on fishing success, while June and July were positive contributors (Table 6). Year 3 was not significant, but all other years 
represented decreased fishing success (Table 6). Soak time, fishing depth, gangion length, and hook distance all contributed positively to fishing success (Table 6). The model represents a strong $33 \%$ improvement over the null model $\left(R_{M c F}^{2}=\right.$ $0.330)$.

Table 6. The Results of the Binomial Regression Model for Mutton Snapper Derived by Backwards Regression $R_{M c F}^{2}=0.330, p<0.01$

\begin{tabular}{|l|c|c|c|}
\hline & Estimate & Std. Error & $p$-value \\
\hline Intercept) & -6.789 & 0.244 & 0.000 \\
\hline CalcSoakTime & 0.170 & 0.012 & 0.000 \\
\hline FishingDepth & 0.008 & 0.001 & 0.000 \\
\hline GangLength & 0.130 & 0.012 & 0.000 \\
\hline HookDistance & 0.017 & 0.003 & 0.000 \\
\hline MonthAug & -1.306 & 0.217 & 0.000 \\
\hline MonthDec & -0.791 & 0.212 & 0.000 \\
\hline MonthFeb & -0.386 & 0.195 & 0.048 \\
\hline MonthJan & -0.867 & 0.209 & 0.000 \\
\hline MonthJul & 3.005 & 0.130 & 0.000 \\
\hline MonthJun & 2.057 & 0.133 & 0.000 \\
\hline MonthMar & -0.442 & 0.192 & 0.022 \\
\hline MonthMay & -0.717 & 0.220 & 0.001 \\
\hline MonthNov & -0.046 & 0.169 & 0.786 \\
\hline MonthOct & -2.660 & 0.380 & 0.000 \\
\hline MonthSep & -1.063 & 0.202 & 0.000 \\
\hline Year2 & -3.314 & 0.212 & 0.000 \\
\hline Year3 & -13.838 & 122.987 & 0.910 \\
\hline Year4 & -3.689 & 0.254 & 0.000 \\
\hline Year5 & -1.984 & 0.132 & 0.000 \\
\hline Year6 & -3.819 & 0.149 & 0.000 \\
\hline Year7 & -6.699 & 0.592 & 0.000 \\
\hline Year8 & -2.354 & 0.130 & 0.000 \\
\hline Year9 & -1.794 & 0.205 & 0.000 \\
\hline & & & \\
\hline & & & \\
\hline
\end{tabular}

Scamp

The final model for scamp predicts fishing success with soak time, fishing depth, gangion length, month, and year (Table 7). No issues with VIF or influential points were identified, and the model was a significant improvement from the null model $(p<0.01)$. All months represented a significant increase in success over the April baseline except for September and November, which were not significant (Table 7). Years 3, 6, and 9 were not significantly different 
from year 1, but years 2, 4, 5, 8, and 9 all represented a significant improvement in fishing success (Table 7). Fishing depth and gangion length contributed positively, but soak time significantly decreased fishing success (Table 7). The model represents an $18.3 \%$ improvement over the null model $\left(R_{M c F}^{2}=0.183\right)$.

Table 7. The Results of the Binomial Regression Model for Scamp Derived by Backwards Regression $R_{M c F}^{2}=0.183, p<0.01$

\begin{tabular}{|l|c|c|c|}
\hline & Estimate & Std. Error & $\boldsymbol{p}$-value \\
\hline (Intercept) & -10.172 & 0.185 & 0.000 \\
\hline CalcSoakTime & -0.098 & 0.012 & 0.000 \\
\hline FishingDepth & 0.024 & 0.000 & 0.000 \\
\hline GangLength & 0.099 & 0.006 & 0.000 \\
\hline MonthAug & 0.327 & 0.068 & 0.000 \\
\hline MonthDec & 0.394 & 0.073 & 0.000 \\
\hline MonthFeb & 0.295 & 0.060 & 0.000 \\
\hline MonthJan & 0.527 & 0.065 & 0.000 \\
\hline MonthJul & 0.216 & 0.063 & 0.001 \\
\hline MonthJun & 0.335 & 0.058 & 0.000 \\
\hline MonthMar & 0.285 & 0.063 & 0.000 \\
\hline MonthMay & 0.696 & 0.063 & 0.000 \\
\hline MonthNov & 0.180 & 0.076 & 0.018 \\
\hline MonthOct & 0.244 & 0.083 & 0.003 \\
\hline MonthSep & 0.019 & 0.075 & 0.801 \\
\hline Year2 & 0.736 & 0.176 & 0.000 \\
\hline Year3 & -12.591 & 67.275 & 0.852 \\
\hline Year4 & 0.568 & 0.166 & 0.001 \\
\hline Year5 & 0.897 & 0.159 & 0.000 \\
\hline Year6 & 0.096 & 0.159 & 0.547 \\
\hline Year7 & 0.508 & 0.164 & 0.002 \\
\hline Year8 & 1.039 & 0.157 & 0.000 \\
\hline Year9 & -0.141 & 0.171 & 0.410 \\
\hline
\end{tabular}

\section{Gag Grouper}

The model for gag grouper predicts fishing success with soak time, fishing depth, gangion length, hook count, month, and year (Table 8). No issues with VIF or influential points were identified, and the model was a significant improvement from the null model $(p<0.01)$. Fishing depth, gangion length, and hook count increased success, and soak time decreased fishing success (Table 8). All months were significant improvements over the April baseline (Table 8). Years 3, 6, and 7 
were not significant, but all other years represent an increase in fishing success. The model was a $9 \%$ improvement over the null model $\left(R_{M c F}^{2}=0.090\right)$.

Table 8. The Results of the Binomial Regression Model for Gag Grouper Derived by Backwards Regression $R_{M c F}^{2}=0.090, p<0.01$

\begin{tabular}{|l|c|c|c|}
\hline & Estimate & Std. Error & $\boldsymbol{p}$-value \\
\hline (Intercept) & -8.939 & 0.192 & 0.000 \\
\hline CalcSoakTime & -0.097 & 0.016 & 0.000 \\
\hline FishingDepth & 0.015 & 0.000 & 0.000 \\
\hline GangLength & 0.054 & 0.007 & 0.000 \\
\hline Hooks & 0.000 & 0.000 & 0.000 \\
\hline MonthAug & 0.750 & 0.093 & 0.000 \\
\hline MonthDec & 0.918 & 0.089 & 0.000 \\
\hline MonthFeb & 0.432 & 0.091 & 0.000 \\
\hline MonthJan & 0.533 & 0.102 & 0.000 \\
\hline MonthJul & 0.142 & 0.099 & 0.153 \\
\hline MonthJun & 0.326 & 0.087 & 0.000 \\
\hline MonthMar & 0.562 & 0.086 & 0.000 \\
\hline MonthMay & 1.134 & 0.083 & 0.000 \\
\hline MonthNov & 0.413 & 0.098 & 0.000 \\
\hline MonthOct & 0.688 & 0.098 & 0.000 \\
\hline MonthSep & 0.730 & 0.087 & 0.000 \\
\hline Year2 & 1.481 & 0.169 & 0.000 \\
\hline Year3 & -0.942 & 0.474 & 0.047 \\
\hline Year4 & 0.885 & 0.167 & 0.000 \\
\hline Year5 & 0.846 & 0.157 & 0.000 \\
\hline Year6 & -0.333 & 0.161 & 0.038 \\
\hline Year7 & 0.116 & 0.169 & 0.494 \\
\hline Year8 & 0.956 & 0.154 & 0.000 \\
\hline Year9 & 0.499 & 0.174 & 0.004 \\
\hline
\end{tabular}

Red Porgy

The final model for red porgy predicts success as a function of fishing depth, gangion length, hook distance, mainline length, month, and year (Table 9). No issues with VIF or influential points were identified, and the model was a significant improvement from the null model $(p<0.01)$. Fishing depth and gangion length increases resulted in increased red porgy fishing success, whereas hook distance and mainline length were negative contributors (Table 9). Months August, January, November, and September were not significantly different from the April baseline; February and December saw decreased fishing success, 
whereas March, May, June, July, and October resulted in fishing success improvement. The model represents an $12 \%$ improvement over the null model $\left(R_{M c F}^{2}=0.120\right)$.

Table 9. The Results of the Binomial Regression Model for Red Porgy Derived by Backwards Regression $R_{M c F}^{2}=0.120, p<0.01$

\begin{tabular}{|c|c|c|c|}
\hline & Estimate & Std. Error & $p$-value \\
\hline (Intercept) & -9.420 & 0.385 & 0.000 \\
\hline FishingDepth & 0.022 & 0.001 & 0.000 \\
\hline GangLength & 0.124 & 0.019 & 0.000 \\
\hline HookDistance & -0.025 & 0.005 & 0.000 \\
\hline MainLineMi & -0.131 & 0.036 & 0.000 \\
\hline MonthAug & 0.424 & 0.233 & 0.069 \\
\hline MonthDec & -1.143 & 0.368 & 0.002 \\
\hline MonthFeb & -1.198 & 0.249 & 0.000 \\
\hline MonthJan & -0.105 & 0.215 & 0.624 \\
\hline MonthJul & 0.536 & 0.200 & 0.007 \\
\hline MonthJun & 1.195 & 0.166 & 0.000 \\
\hline MonthMar & 0.507 & 0.187 & 0.007 \\
\hline MonthMay & 0.568 & 0.206 & 0.006 \\
\hline MonthNov & -0.305 & 0.303 & 0.315 \\
\hline MonthOct & 0.939 & 0.228 & 0.000 \\
\hline MonthSep & -0.287 & 0.247 & 0.245 \\
\hline Year2 & -2.033 & 0.485 & 0.000 \\
\hline Year3 & -12.895 & 195.088 & 0.947 \\
\hline Year4 & -0.721 & 0.296 & 0.015 \\
\hline Year5 & -1.172 & 0.250 & 0.000 \\
\hline Year6 & -1.385 & 0.243 & 0.000 \\
\hline Year7 & -1.006 & 0.280 & 0.000 \\
\hline Year8 & -1.808 & 0.244 & 0.000 \\
\hline Year9 & -0.599 & 0.322 & 0.063 \\
\hline
\end{tabular}

\section{Discussion}

\section{Research Implications}

The results of this study indicate that manipulating gear and set parameters can effectively increase the likelihood of a fisher catching their target species and reduce bycatch of other fishes. Over the last few decades, bycatch reduction strategies have become a priority for fishery managers (Alverson and Hughes, 
1996; Hall et al., 2000; Kennelly and Broadhurst, 2002; Rodger and von Zharen, 2011). Prior research has focused on individual fishery variables (e.g., Erzini et al., 1996; Erzini et al., 1998; Hall et al., 2000; Belda and Sánchez, 2001; Coelho et al., 2003; Piovano et al., 2010; Mitchell, 2014), but these variables do not represent a comprehensive model for improving target species catch success. This study represents the first attempt to provide a model for improving the catch success rate for reef fishes on a species-specific basis.

The methods employed herein can be applied in any fishery with sufficient data, and may contribute to a reduction of non-target species bycatch on a large scale. All fishery management plans (FMPs) in the United States must be based on "the best scientific information available," per National Standard 2 (50 CFR Ch. VI $\S 600.315)$. This includes biological, ecological, economic, and social information, and requires thorough analysis by managers before implementing any regulations. However, we suggest that the factors currently addressed in this mandate are incomplete, and an analysis of existing fishing methods and suggestions for best practices should be included if the fishery is actively being exploited. The results contained herein will enhance the management of Gulf of Mexico longline reef fish fisheries through addressing best fishing practices at a species-specific level. Additionally, implementing regulation regarding gear and set parameters is likely to be well received by fishers. These changes should ultimately reduce capital expenditure necessary to catch their target species. Prior research lacks a comprehensive model for the most effective methods to target these reef fish species.

Porgys

Neither red nor jolthead porgys have been federally regulated with catch or total length limits during the study period. Jolthead porgy fishing success was increased with increasing fishing depth, gangion length, mainline length, and hook count. Month and year both contributed in the fishing success model suggesting a seasonal fishing success trend. The months of June, July, and August had significantly reduced fishing success when compared to the April baseline, whereas all other months saw significantly greater fishing success than April. This result suggests that fishing for jolthead porgys is most successful from September to May, and lower in the summer months. Seasonal closure per GMRFFMP amendment 31 likely contributed to the decline in catch success in June through August. A slight decline in fishing success occurred in year 2 (2007), but all other years except year 7 (2012) saw significantly greater fishing success than the year 1 (2006) baseline. These results should be considered by managers when determining the fishing seasons.

Red porgy fishing success increased significantly with gangion length and fishing depth, but declined with hook distance and mainline length. Fishing success was significantly lower in December and February, and significantly higher in the spring and summer (March, May, June, July, and October). Interestingly, the 30 fathom closure (GMPRFFMP amendment 31) does not appear to have influenced red porgy catch success. Year in the fishing success 
model suggests an overall decline in red porgy fishing success, with only years 3 and 9 (2008 and 2014) not significantly lower than year 1 . The results of this model suggest that increasing fishing depth and decreasing hook distance are the most important for catching red porgys. Spring and summer are the best times to catch large and retainable red porgys. However, the overall decline in fishing success from year 1 indicates that either fishers are keeping fewer red porgys, or that overall fishing success is declining. Further study is necessary to assess whether a population decline is occurring, and whether federal regulation has become necessary.

\section{Snappers}

Throughout the study period, mutton snappers have been regulated with a 16-inch total length minimum but no quotas or trip limits. Fishing depth, soak time, gangion length, and hook distance all contributed to increased fishing success. August, September, October, December, January, and March, and May saw significantly lower fishing success than the April baseline. June and July appear to be the best times for fishing, as these months were the only months with positive coefficients. This species appears largely uninfluenced by the spatial closure (GMRFFMP amendment 31). The annual trend in the fishing success model suggests an overall decline in kept mutton snapper. Further research is necessary to determine whether this is due to fisher selection or a population decline requiring federal regulation to reverse.

Red snapper fishing success was significantly improved with increasing fishing depth, gangion length, and hook count, and declined with mainline length. Mitchell (2014) indicates that reducing soak time may reduce shark bycatch, but this reduction may be small: soak time does not figure into the red snapper overall model. June, July, and August had significantly lower fishing success, but all other months were significantly higher than the April baseline. Seasonal closure per GMRFFMP amendment 31 likely contributed to the decline in catch success in June through August. Red snapper regulation has changed dramatically over time with the initiation of the IFQ system in 2008 and quota increases in 2010, 2012, and 2013, and a decrease in the total length requirement from 15 inches to 13 inches in 2008. While year 2 (2007) had significantly lower fishing success, all other years except year 7 (2012) had significantly increased fishing success when compared with year 1. In the length model, all years saw significantly increased length. These results suggest that the IFQ system has been extremely effective in regulating red snapper.

\section{Groupers}

Speckled hind fishing success improved significantly with fishing depth and hook count. The greatest speckled hind success compared with the April baseline was recorded in the months of October, November, and March, indicating that the winter months may be the best time for catching speckled hind. While year was significant within the model, no individual year deviated significantly from 
the year 1 baseline. Interestingly, speckled hind management has changed dramatically over the study period, with the species being moved from the deepwater grouper to shallow-water grouper quota in 2010, and the quota lowered in 2012. Despite these regulatory changes, fishing success of speckled hind has not changed between 2006 and 2014.

Red grouper fishing success improved significantly with mainline length and hook count, but declined with fishing depth, gangion length, and hook distance. Prior research suggests that reducing soak time may reduce elasmobranch bycatch (Mitchell, 2014). However, this reduction does not figure into the overarching bycatch reduction model, and may only provide a small reduction in bycatch. Seasonality plays an important role in red grouper fishing success, with significantly lower success in March, June, July, August, and November, and significantly higher success in September, October, December, January, and February when compared with the April baseline. Red grouper are one of the most frequently targeted reef fish species in the Gulf of Mexico, and seasonal closure per GMRFFMP amendment 31 appeared to impact fishing success greatly with declines in the restricted fishing months. The red grouper catch quota was raised in 2009, and lowered in 2012, with the total length minimum raised in 2008. Despite these changes, all years showed significantly greater fishing success when compared with the year 1 baseline, with greater gains in later years.

Scamp fishing success improved with fishing depth and gangion length and declined with soak time. All months except September and November had significantly higher fishing success than the April baseline, and scamp were uninfluenced by the seasonal closure (GMRFFMP amendment 31). The catch quota for scamp was lowered in 2009, raised in 2010, and lowered again in 2012. Significant increases in fishing success when compared with the year 1 baseline were recorded in years 2 (2007), 4 (2009), 5 (2010), 7 (2012), and 8 (2013). This indicates that quota changes did not negatively impact fishing success, as increases were documented in the periods surrounding the quota lowering.

Gag grouper fishing success increased significantly with fishing depth, gangion length, and hook count, and declined with soak time. All months except July had significantly greater fishing success than the April baseline. This suggests that while the summer months may be slightly worse for catching gag grouper and seasonal closures may have played a role, but in general fishing year-round is successful. The gag grouper total length requirement was lowered in 2013. Gag was given a separate quota in year 4 (2009), which was lowered in 2010. In 2011, an emergency rule limited the total catch to less than half a million pounds and the quota was lowered dramatically in 2012. Year was significant in the length model, but only year 6 (2011) deviated significantly from year 1 . Significant increases in fishing success were documented in year 2 (2007), 4 (2009), 5 (2010), 8 (2013), and 9 (2014). These increases in fishing success in later years indicate that the quota changes effectively improved fishing success, though further research is required to assess whether this improvement occurred at the population level or resulted from reduced fishing effort. 


\section{Conclusions and Future Directions}

The results of this study indicate that altering fishing practices can influence the success of obtaining a target species, or legally retainable bycatch species. Changing fishing practices to reflect the outcome of these models may reduce bycatch of non-target species or individuals of the target species which are not legally retainable. Through the utilization of these models, fishers can maximize their catch, thereby reducing the time and capital spent to obtain fish. Bycatch reduction may have long term positive environmental impacts.

This study represents the first to include hook placement and proximity influences on species selectivity. Gangion length, hook distance, hook count, or a combination of these factors was included in every selectivity model derived herein. Future research in longline fishing selectivity should address these factors, as they quantify the spatial proximity of the fish to each other during fishing. Whether species are solitary or schooling, interactions with other fish (caused by hooks located close together, on short gangions, or because of the number of hooks set) may influence species selectivity.

Further study is necessary to quantify whether the changes over time that have been recorded are a result of improved population strength or a function of increased fishing success. However, in general, most species saw an improvement in fishing success over time. Two species, red porgy and mutton snapper, saw declines over the study period. Interestingly, these two species have not been federally regulated by catch quotas and only mutton snapper have a total length limit in place. While some state regulations are in place, these declines suggest that federal management intervention may be appropriate to prevent further fishing success declines in the future.

The results of this study ultimately indicate that manipulating gear and set parameters and seasonality may have an influence on the ability of fishers to successfully obtain the targeted species. Fishers should consider implementing the gear configuration recommendations contained herein to improve their fishing success and reduce the resources expended to catch the desired amount of fish. When considered in tandem with the length maximization models under study currently, fishers can make informed decisions regarding the best fishing practices. Although these models do not guarantee that fishers will always catch the desired species, using these recommendations as a guide may ultimately contribute to reduced bycatch and improved fishing success.

\section{Acknowledgments}

Our thanks to the many fishery observers, coordinators, and data entry personnel for their tremendous efforts in data collection, and to the commercial fishers who facilitated observation. Special thanks to Dr. Elizabeth Scott-Denton and the NOAA Southeast Fisheries Science Center Galveston Laboratory for facilitating this study and for their helpful comments on this publication. 


\section{References}

Allison, P. D. 2014. Measures of Fit for Logistic Regression. SAS Global Forum, Washington, DC.

Alverson, D. L. 1999. Some observations on the science of bycatch. Marine Technology Society. Marine Technology Society Journal 33: 6.

Alverson, D. L., and S. E. Hughes. 1996. Bycatch: from emotion to effective natural resource management. Reviews in Fish Biology and Fisheries 6: 443-462.

Belda, E. J., and A. Sánchez. 2001. Seabird mortality on longline fisheries in the western Mediterranean: factors affecting bycatch and proposed mitigating measures. Biological Conservation 98: 357-363.

Chuenpagdee, R., L. E. Morgan, S. M. Maxwell, E. A. Norse, and D. Pauly. 2003. Shifting gears: assessing collateral impacts of fishing methods in US waters. Frontiers in Ecology and the Environment 1: 517-524.

Coelho, R. et al. 2003. Reduction of elasmobranch by-catch in the hake semipelagicnearbottom longline fishery in the Algarve (Southern Portugal). Fisheries Science 69: 293-299.

Davis, M. W. 2005. Behavior impairment in captured and released sablefish: ecological consequences and possible substitute measures for delayed discard mortality. Journal of Fish Biology 66: 254-265.

Erzini, K., J. M. Gonçalves, L. Bentes, P. G. Lino, and J. Cruz. 1996. Species and size selectivity in a Portuguese multispecies artisanal long-line fishery. ICES Journal of Marine Science: Journal du Conseil 53: 811-819.

Erzini, K., L. Bentes, P. G. Lino, and J. Ribeiro. 1998. Species and size selectivity in a 'red' sea bream longline 'métier' in the Algarve (southern Portugal). Aquatic Living Resources 11: 1-11.

Gulf of Mexico Fishery Management Council. 2010a. Allowable Fishing Gear in Federal Waters of the Gulf of Mexico. http://bit.ly/2AI2XMt. [Accessed 21 September 2016].

Gulf of Mexico Fishery Management Council. 2010b. Reef Fish Management Plans Archives. http://bit.ly/2zIXtld.

Gulf of Mexico Fishery Management Council. 2015. Species listed in the fishery management plans of the Gulf of Mexico Fishery Management Council. http://bit. ly/2yEg4xA.

Hall, M. A., D. L. Alverson, and K. I. Metuzals. 2000. By-catch: problems and solutions. Marine pollution bulletin 41: 204-219.

Huse, I., and A. V. Soldal. 2000. An attempt to improve size selection in pelagic longline fisheries for haddock. Fisheries Research 48: 43-54.

Kennelly, S. J., and M. K. Broadhurst. 2002. By-catch begone: changes in the philosophy of fishing technology. Fish and Fisheries 3: 340-355.

Lewison, R. L., L. B. Crowder, A. J. Read, and S. A. Freeman. 2004. Understanding impacts of fisheries bycatch on marine megafauna. Trends in Ecology \& Evolution 19: 598-604.

Mitchell, J. 2014. Southeast U.S. Fisheries Bycatch Reduction Technology. In: Marine Resource Education Program Southeast Science Workshop, St. Petersburg, Florida.

National Marine Fisheries Service. 2013. Characterization of the US Gulf of Mexico and Southeastern Atlantic Otter Trawl and Bottom Reef Fish Fisheries Observer Training Manual, National Oceanic and Atmospheric Administration, Southeast Fisheries Science Center Galveston Laboratory, 181 pgs.

NOAA Fisheries. 2016. Draft National Bycatch Reduction Strategy. p 9. National Oceanic and Atmospheric Administration. 
Pikitch, E. K. et al. 2004. Ecosystem-Based Fishery Management. Science 305: 346-347.

Piovano, S., S. Clò, and C. Giacoma. 2010. Reducing longline bycatch: The larger the hook, the fewer the stingrays. Biological Conservation 143: 261-264.

Rodger, R. W. A., and W. M. von Zharen. 2011. The Commercial Fisheries of the United States and Canada, Illustrated 2012 Edition Canadian Marine Publications, Halifax, Nova Scotia, Canada.

Scott-Denton, E. et al. 2011. Descriptions of the US Gulf of Mexico reef fish bottom longline and vertical line fisheries based on observer data. Marine Fisheries Review 73: $1-26$.

Scott-Denton, E., and J. A. Williams. 2013. Observer Coverage of the 2010-2011 Gulf of Mexico Reef Fish Fishery, NOAA Technical Memorandum NMFS-SEFSC646.

Southwood, A., K. Fritsches, R. Brill, and Y. Swimmer. 2008. Sound, chemical, and light detection in sea turtles and pelagic fishes: sensory-based approaches to bycatch reduction in longline fisheries. Endangered Species Research 5: 225-238.

Waters, J. R. 2001. Quota management in the commercial red snapper fishery. Marine Resource Economics 16: 65-78.

Watson, J. W., and D. W. Kerstetter. 2006. Pelagic longline fishing gear: A brief history and review of research efforts to improve selectivity. Marine Technology Society Journal 40: 6-11. 